\title{
Fermentação Ruminal e Eficiência Microbiana em Bezerros Holandeses Alimentados com Dietas Contendo Diferentes Níveis de Concentrado ${ }^{1}$
}

\section{Peter Johann Bürger ${ }^{2}$, José Carlos Pereira ${ }^{3}$, Sebastião de Campos Valadares Filho ${ }^{3}$, José Fernando Coelho da Silva ${ }^{3}$, Augusto César de Queiroz ${ }^{3}$, Paulo Roberto Cecon $^{4}$, Doriedson Magiero}

\begin{abstract}
RESUMO - Este trabalho foi realizado para avaliar os efeitos de diferentes níveis de concentrado sobre os parâmetros da fermentação ruminal, as digestibilidades aparente, total, ruminal e intestinal de N, a eficiência microbiana e o balanço de N. Cinco bezerros holandeses, inteiros, fistulados no rúmen e abomaso, com idade média inicial de 5,8 $\pm 0,7$ meses e 107,4 $\pm 11,0 \mathrm{~kg}$ PV médio inicial, foram distribuídos em quadrado latino $5 \times 5$ (tratamento x período). Os animais foram alojados em baias individuais e alimentados à vontade com dietas contendo 30,0; 45,0; 60;0; 75,0; e 90,0\% de concentrado, com base na MS, em rações contendo como volumoso, o feno de capim coastcross e no concentrado, o farelo de soja, fubá de milho. Os valores de $\mathrm{pH}$ foram influenciados pelos níveis de concentrado das rações, e , 11,3 horas após a alimentação, foram estimandos os valores mínimos de 6,10;5,89;5,67; 5,46; e 5,24, para as rações com níveis de 30,0; 45,0; 60,0; 75,0; e 90,0\% de concentrado nas rações, respectivamente. A concentração de amônia ruminal reduziu linearmente, em função dos tempos pós-alimentação, apresentando comportamento quadrático, com valores mínimos de 6,84; 7,14; 7,63; 7,82; 8,09; e $8,00 \mathrm{mg} / \mathrm{dL}$, para 86,$31 ; 84,86 ; 83,41 ; 81,95 ; 77,59 ;$ e $68,86 \%$ de concentrado nas rações. O numero de protozoários ruminais reduziu linearmente com o aumento dos níveis de concentrado nas rações. A eficiência de síntese de compostos nitrogenados microbianos aumentou linearmente com os níveis de concentrado nas rações.
\end{abstract}

Palavras-chave: amônia, bezerros holandeses, concentrado, eficiência microbiana, $\mathrm{pH}$, protozoários ruminais

\section{Ruminal Fermentation and Microbial Efficiency in Holstein Calves Fed Diets with Different Concentrate Levels}

\begin{abstract}
This work was conducted to evaluate the effects of different concentrate levels on the parameters of at ruminal fermentation, the apparent, total, ruminal and intestinal $\mathrm{N}$ digestibilities, the microbial efficiency and the $\mathrm{N}$ balance. Five rumen and abomasum fistulated bull Holstein calves, with an initial average age of $5.8 \pm 0.7$ months and initial average of $107.4 \pm 11.0 \mathrm{~kg} \mathrm{LW}$ were allotted to a 5x5 Latin square design (treatment x period). The animals were housed in individual stalls and full fed diets (DM basis) containing $30.0,45.0,60.0,75,0$ and $90.0 \%$ of concentrate. The diets were based on coast-cross grass hay as forage and soybean meal and corn ground grain in the concentrate. The $\mathrm{pH}$ values were affected by the concentrate levels of the diets, and, 11.3 hours post-feeding, the minimum values of $6.10,5.89,5.67,5.46$, and 5.24, respectively, were estimated for the diets with $30.0,45.0,60.0,75.0 \mathrm{e} 90.0 \%$ of concentrate in the diets, respectively. The ruminal ammonia concentration linearly decreased, in function of post-feeding time and showing quadratic behavior, with a minimum values of $6.84,7.14,7,40,7.63,7.82,8.09$, and $8.00 \mathrm{mg} / \mathrm{dL}$, for 86.31, 84.86, 83.41, 80,50, $81.95,77.59$, and $68.86 \%$ of concentrate in the diets. The number of ruminal protozoa linearly reduced as the dietary concentrate levels increased. The efficiency of microbial nitrogenous compound synthesis linearly increased, as the concentrate levels in the diets increased.
\end{abstract}

Key Words: ammonia, Holstein calves, concentrate, microbial efficiency, pH, ruminal protozoa

\section{Introdução}

$\mathrm{O}$ pH do conteúdo ruminal reflete o balanço entre as taxas de produção de ácidos graxos voláteis, o influxo de tampões por meio da saliva e a presença ou liberação de tampões ou bases dos alimentos. Dietas ricas em concentrado são ingeridas rapidamente, requerendo baixo tempo de ruminação e reduzindo a taxa de secreção salivar em relação à produção de ácidos graxos voláteis (ERFLE et al., 1982; OWENS e GOETSCH, 1988; e ØRSKOV, 1994).

As dietas devem ser balanceadas para a manutenção de $\mathrm{pH}$ ruminal adequado, estando sua variação relacionada à frequiência de alimentação e à adaptação à dieta; o decréscimo do $\mathrm{pH}$ ruminal provoca depressão do apetite, da motilidade ruminal,

\footnotetext{
1 Parte da Tese de Doutorado do primeiro autor.

2 Professor Nível IV do CAV-UDESC, 88520-000 - Lages, SC. E.mail: a2pjb@cav.udesc.br

3 Professor Titular do DZO-UFV. Bolsista do CNPq. E.mail: jearper@mail.ufv.br

${ }^{4}$ Professor Adjunto do DPI-UFV.

${ }^{5}$ Bolsista de Iniciação Científica do CNPq
} 
do crescimento microbiano e da digestão da fibra, podendo ocasionar laminites, ulcerações ruminais, abcessos hepáticos e até morte (ALLEN, 1997).

Valores mínimos de $\mathrm{pH}$ ruminal de 12 a 14 horas após a alimentação foram relatados por vários autores (FARIA e HUBER, 1984; FRANZOLIN e DEHORITY, 1996). O abaixamento do $\mathrm{pH}$ ruminal ocorre, principalmente, após a ingestão rápida de alimento, no caso de grãos de cereais moídos, por secreção salivar insuficiente para a manutenção do pH entre 6 e 7, e a inadequada estrutura física, para estimular a motilidade ruminal e a ruminação (ØRSKOV, 1986).

Há variação nos dados relatados na literatura sobre os valores das concentrações de amônia ruminal, requeridos para atender o crescimento máximo dos microrganismos ruminais: $5 \mathrm{mg} / \mathrm{dL}$ (SATTER e ROFFLER, 1975); 23,5 mg/dL (MEHREZ et al., 1977); $9 \mathrm{mg} / \mathrm{dL}$ e $29 \mathrm{mg} / \mathrm{dL}$ (Hume et al.,1970 e Miller, 1973, citados, respectivamente por STERN e HOOVER, 1979); 6,3 a 27,5 mg/dL (ORTEGA et al., 1979); e 3,3 a 8,5 mg/dL (KANG-MERZNARICH e BRODERICK, 1981).

Vários trabalhos revisados na literatura relataram a redução na concentração de amônia ruminal, em função da elevação do nível de concentrado nas dietas (McALLAN,1991; KUNG et al.,1992; GRIGSBY et al., 1993; FENG et al., 1993; MURPHY et al.,1994; e CARVALHO, 1996).

TOWNE et al. (1990) e DIJKSTRA (1994) mencionaram que, em bovinos confinados, com consumo de concentrado ad libitum, a concentração de protozoários ciliados ruminais foi reduzida ou completamente eliminada, sendo sua sobrevivência influenciada pelo tempo de alimentação com concentrados e pela proporção volumoso: concentrado, em virtude da ingestão de quantidades crescentes de amido, nas dietas com níveis mais elevados de concentrado.

RINNE et al. (1997), que alimentaram novilhos holandeses com dietas constituídas de silagem de capim, em quatro estádios de maturidade e cevada e farelo de colza, à base de $70 \mathrm{~g} \mathrm{MS} / \mathrm{kg} \mathrm{PV}^{0,75}$, nas proporções de 700, 240 e 60 g MS do total de MS, mostraram não ter ocorrido variação na contagem de protozoários ruminais, respectivamente, $74 \times 10^{4}$, $62 \times 10^{4}, 53 \times 10^{4}, 54 \times 10^{4}$ cél./mL.

De acordo com CLARK et al. (1992), determinar a composição das bactérias ruminais é importante, porque as dietas são formuladas para que os aminoácidos que escapam da degradação ruminal complementem os aminoácidos bacterianos. Para estimar o fluxo de proteína bacteriana para o intestino delgado, esses autores não recomendam a utilização de dados médios encontrados na literatura, da composição das bactérias ruminais, pela grande variação nos valores relatados.

Entre os fatores responsáveis pela variação na composição dos microrganismos ruminais, incluemse o tipo de microbiota e sua fase de crescimento, a disponibilidade de nutrientes, as alterações na dieta e a variação na freqüência de alimentações (JOHN, 1984; National Research Council - NRC, 1985).

Os dados sobre o conteúdo em RNA das bactérias mostram variação bastante acentuada, de 3,5 e 5,0 g/100 g MS para bactérias aderentes e livres, respectivamente (MERRY e McALLAN, 1983) até 12 g/100 g MS (JOHN, 1984). Esta variação em parte é atribuída aos diferentes métodos de análise utilizados, mas, por outro lado, reflete também o nível de atividades metabólicas das bactérias (BATES et al., 1985).

Em estudos sobre eficiência de síntese de proteína microbiana, HAGEMEISTER et al. (1981) relataram os valores de 18,0;22,0; e 16,8 g/100 g de matéria orgânica digerível no rúmen (MODR), para os níveis de 0 a $20 \%, 30$ a $70 \%$ e 70 a $100 \%$ de concentrado, respectivamente.

Os objetivos deste trabalho foram avaliar os efeitos de diferentes níveis de concentrado, sobre parâmetros da fermentação ruminal e eficiência microbiana em bezerros holandeses.

\section{Material e Métodos}

O local, a época, as condições climáticas do experimento, os animais, o manejo, as instalações e as dietas experimentais foram descritos por BÜRGER et al. (2000).

Cada período experimental teve duração de 29 dias, sendo as coletas de líquido ruminal para dosagens de amônia, $\mathrm{pH}$ e protozoários efetuadas entre o $21^{\circ}$ e $22^{\circ}$ dias; e a coleta de líquido ruminal, para a determinação da composição microbiana, no $29^{\circ}$ dia.

Por meio de uma bomba manual de vácuo, efetuaram-se coletas de amostras de líquido de rúmen, de $100 \mathrm{~mL}$, as quais foram filtradas em tecido de gaze de algodão duplo, acondicionadas em frascos de vidro com tampa de polietileno e congeladas a $-10^{\circ} \mathrm{C}$, em cada período experimental, nos tempos 0 (pré-alimentação) e $2 ; 4 ; 6 ; 8 ; 12$; e 24 horas pós-alimentação, para determinação do $\mathrm{pH}$ e concentração de amônia. Coletaram-se, com procedimentos e tempos idênticos aos adotados para o pH e amônia, $50 \mathrm{~mL}$ de 
Rev. bras. zootec.

líquido de rúmen para a contagem de protozoários.

Foram coletadas, nos períodos experimentais, por animal, seis amostras de digesta abomasal com cerca de $50 \mathrm{~mL}$, a intervalos de 28 horas, após compostas, por período, acondicionadas em frascos de vidro com tampas de polietileno e conservadas em congelador a $-10^{\circ} \mathrm{C}$, para posterior análise de amônia.

Para o isolamento das bactérias ruminais, em cada período experimental, foram coletadas, por animal, amostras de cerca de 1,5 L de digesta sólida e líquida do rúmen, adicionando-se $0,5 \mathrm{~L}$ de solução fisiológica (CECAVA et al., 1990), homogeneizandose manualmente por cerca de três minutos, sendo filtradas em tela de náilon e obtidas amostras de cerca de $2,0 \mathrm{~L}$, armazenadas a $-10^{\circ} \mathrm{C}$, em frascos de plástico com tampa rosqueada.

$\mathrm{O} \mathrm{pH}$ do fluido ruminal foi determinado imediatamente após a coleta, utilizando-se potenciômetro digital. Posteriormente à determinação do $\mathrm{pH}$, adicionou-se, às mesmas amostras, 1,0 mL de ácido sulfúrico a $50 \%$, sendo congeladas a $-10^{\circ} \mathrm{C}$, para posterior determinação de amônia.

A concentração de amônia nas amostras de digesta do rúmen e do abomaso foi determinada, após descongelamento e decantação, de acordo com técnica descrita por FENNER (1965), com as adaptações propostas por VIEIRA (1980).

Os procedimentos para fixação dos protozoários ruminais seguiram as recomendações descritas por DEHORITY (1984), empregando-se a diluição 1:2 de líquido ruminal e formaldeído. Para contagem dos protozoários nas amostras de fluido ruminal formalizado, utilizaram-se subamostras de $1,0 \mathrm{~mL}$, sendo a leitura procedida em câmara de Neubauer, com 0,1 mm de profundidade, conforme WARNER (1962), com microscópio óptico binocular, resolução de 300 , e enumeração obtida a partir da média da leitura de dois campos, expressa por número de cél./mL e calculada pela fórmula proposta por FERREIRA NETO (1981).

O isolamento das bactérias das amostras de digesta ruminal foi efetuado por procedimentos de centrifugações diferenciais, conforme técnica citada por CECAVA et al. (1990).

Para a estimativa da eficiência de síntese de compostos nitrogenados microbianos, utilizaram-se as bases purinas como indicador microbiano, determinando-se a concentração do N-purínico ou RNA equivalente em isolado de células bacterianas ruminais de amostras de digesta de rúmen e abomaso, conforme metodologia proposta por USHIDA et al. (1985) e ZINN e OWENS (1986). Os padrões das bases purinas foram preparados com RNA de levedura, nas concentrações de $0 ; 12 ; 20 ; 30$; e 60 mg, diluídas em ácido clorídrico $0,5 \mathrm{~N}$. Procedeu-se à análise de $\mathrm{N}$ total dos padrões de levedura, da digesta do abomaso, das fezes e da urina, conforme SILVA (1990).

O teor de nitrogênio não-amoniacal (NNA) no abomaso foi obtido pela diferença entre a concentração de N-total e $\mathrm{N}-\mathrm{NH}_{3}$ da digesta abomasal.

Procedeu-se à determinação da composição do isolado de células bacterianas ruminais, no tocante aos teores de MS, MO, N e EE, segundo SILVA (1990).

A quantidade de compostos nitrogenados $(\mathrm{N})$ no abomaso foi calculada dividindo-se o fluxo abomasal de N-RNA pela relação N-RNA/N-total das bactérias isoladas no rúmen. Determinou-se o fluxo de MS bacteriana no abomaso pela relação entre o $\mathrm{N}$ microbiano no abomaso e a porcentagem de N na MS microbiana.

Os cálculos das digestibilidades aparentes total e parcial de $\mathrm{N}$, no rúmen e nos intestinos, foram efetuados segundo COELHO DA SILVA e LEÃO (1979).

O experimento foi realizado utilizando-se o delineamento experimental em quadrado latino $5 \times 5$ (cinco animais cinco períodos) com cinco tratamentos, correspondentes aos níveis de 30, 45, 60, 75 e $90 \%$ de concentrado. Os dados experimentais foram analisados empregando-se o programa SAEG-Sistema de Análises Estatísticas e Genéticas, versão 7.1 (UNIVERSIDADE..., 1997). Para efeito de análise estatística da concentração de amônia, do pH e do número de protozoários do rúmen, adotou-se o esquema de parcelas subdivididas, tendo nas parcelas os níveis de concentrado e nas subparcelas os tempos, utilizandose a metodologia da superfície de resposta. Os modelos foram selecionados com base no coeficiente de determinação e na significância dos coeficientes de regressão, adotando-se nível de $5 \%$ de probabilidade pelo teste $\mathrm{F}$.

\section{Resultados e Discussão}

O modelo que melhor se ajustou para os valores de $\mathrm{pH}$ ruminal $\left(\hat{\mathrm{Y}}_{\mathrm{p}}\right)$, em função dos tempos pós-alimentação (t) e dos níveis de concentrado $(C)$, foi $\hat{\mathrm{Y}}_{\mathrm{p}}=7,5092-0,01437 * * \mathrm{C}-0,1724 * * \mathrm{t}+0,007639 * * \mathrm{t}^{2}$ $\left(\mathrm{R}^{2}=0,802 ; \mathrm{P}<0,01\right)$. Na Figura 1, são mostradas as estimativas dos valores de $\mathrm{pH}$ ruminal, observandose comportamento quadrático $(\mathrm{P}<0,01)$, em função 


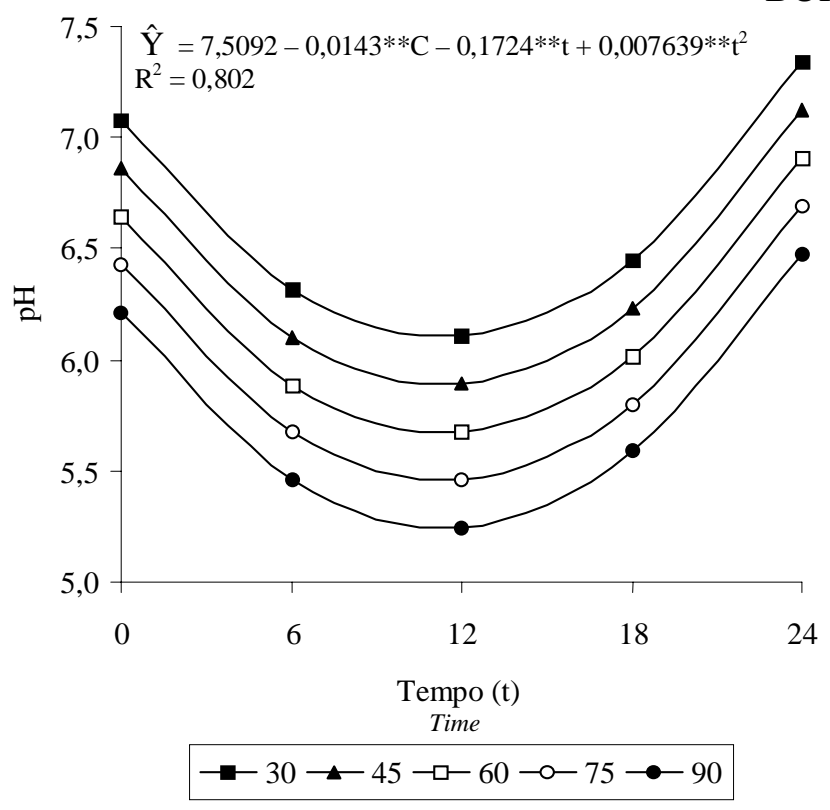

** $(\mathrm{P}<0,01)$ pelo teste $\mathrm{F}$ (by $\mathrm{F}$ test); $\mathrm{C}=$ Nível de concentrado das dietas experimentais (Concentrate levels of experimental diets); $\mathrm{t}=$ Tempo pós-alimentação em horas (Post-feeding time in hours).

Figura 1 - Estimativas do $\mathrm{pH}$ do fluido ruminal, em função dos tempos pós-alimentação (t) em horas, para cada nível de concentrado $(\mathrm{C})$ das dietas experimentais.

Figure 1 - Estimates of rumen fluid $\mathrm{pH}$, as a function of postfeeding time (t), in hours, for each concentrate level of the experimental diets.

dos tempos pós-alimentação (t). Estimou-se que os valores mínimos de pH ocorreram 11,3 horas após a alimentação, sendo obtidos os valores de 6,$10 ; 5,89$; 5,$67 ; 5,46$; e 5,24, respectivamente, para os níveis de $30,45,60,75$ e $90 \%$ de concentrado. Os valores mínimos de $\mathrm{pH}$ ruminal, estimados para 11,3 horas pós-alimentação, estão de acordo com FARIA e HUBER (1984), que trabalharam com novilhos holandeses e observaram menores valores de $\mathrm{pH}, 12$ a 14 horas após a alimentação, os quais se encontram relativamente próximos dos valores de $\mathrm{pH}$ de $6,2 \mathrm{e}$ 5,9, citados por ØRSKOV (1994). Em outro estudo, FRANZOLIN e DEHORITY (1996), que trabalharam com ovinos faunados e defaunados, verificaram igualmente valores mínimos de $\mathrm{pH} 12$ horas após a alimentação. POORE et al. (1990), que trabalharam com novilhos mestiços Zebu com predominância Hereford-Angus, fornecendo níveis de 30; 60; e 90\% de concentrado, relataram variação no $\mathrm{pH}$ ruminal de 6,34 e 5,40. ROBINSON et al. (1986, 1997) também observaram depressão nos valores de $\mathrm{pH}$ ruminal, em função dos tempos pós-alimentação.

As estimativas dos valores de $\mathrm{pH}$ do fluido ruminal, em função dos níveis de concentrado (\%) das dietas experimentais, para os tempos pós-alimentação (t), são apresentadas na Figura 2. Observou-se efeito linear decrescente $(\mathrm{P}<0,01)$ dos níveis de concentrados sobre os valores de $\mathrm{pH}$ para cada tempo pósalimentação. As estimativas dos limites de variação de $\mathrm{pH}$, em função dos níveis de 30 e $90 \%$ de concentrado, para os tempos 24 e 12 horas pós-alimentação, variaram de 7,34 a 5,25, respectivamente. Outros autores igualmente observaram redução do $\mathrm{pH}$ influenciado por níveis crescentes de concentrado (LYLE et al., 1981; McALLAN, 1991).

$\mathrm{O}$ modelo que melhor se ajustou para os valores das estimativas de amônia ( $\hat{\mathrm{Y}}_{\mathrm{a}}$ ) no líquido ruminal, em função dos níveis de concentrado (C) e dos tempos pós-alimentação $(\mathrm{t})$, foi $\hat{\mathrm{Y}}_{\mathrm{a}}=72,6780-$ $1,5252 * * \mathrm{C}+0,008833^{* *} \mathrm{C}^{2}-0,9490^{* *} \mathrm{t}+0,01285^{*} \mathrm{C} . \mathrm{t}$ $\left(R^{2}=0,794 ; P<0,01\right.$; e $\left.P<0,05\right)$. Na Figura 3, encontram-se as equações de regressão e as estimativas das concentrações de amônia $(\mathrm{mg} / 100 \mathrm{~mL})$ no líquido ruminal, em função dos tempos pós-alimentação (t) para os diferentes níveis de concentrado (\%), que apresentaram comportamento linear decrescente, para as inclusões de 30,45 e $60 \%$, e crescente para os níveis de 75 e $90 \%$, respectivamente, com intervalos de 34,9 a $21,3 \mathrm{mg} / \mathrm{dL}, 21,9$ a $13,0 \mathrm{mg} / \mathrm{dL}, 13,0$ a $8,7 \mathrm{mg} / \mathrm{dL}, 8,0$ a $8,3 \mathrm{mg} / \mathrm{dL}$ e 6,9 a $11,9 \mathrm{mg} / \mathrm{dL}$. Vários estudos também relataram redução no teor de amônia ruminal, em função da elevação do nível de concentrado nas dietas (McALLAN, 1991; KUNG et al., 1992; GRIGSBY et al., 1993; FENG et al., 1993; e MURPHY et al., 1994). Entretanto, DUTRA (1996), que pesquisou dietas contendo teores altos e baixos de fibra e fontes protéicas de alta degradação em novilhos, com predominância da raça Pardo-Suíça, não observou variação na concentração ruminal de amônia, devido ao nível de fibra.

As concentrações estimadas de amônia (mg/100 mL), em função dos níveis de concentrado (\%), para os tempos pós-alimentação (t), são apresentadas na Figura 4, observando-se comportamento quadrático. As estimativas das concentrações mínimas de amônia no rúmen, para os tempos 0 (pré-alimentação) e 2; 4; 6; 8; 12; e 24 horas pós-alimentação, foram, respectivamente, 6,84; 7,14; 7,40; 7,63; 7,82; 8,09; e 8,00 mg/dL, correspondendo aos níveis de concentrado de 86,31; 84,86 ; 83,$41 ; 81,95$; 80,50; 77,59; e 68,86\%. As concentrações de amônia ruminal (Figuras 3 e 4 ) foram 
Rev. bras. zootec.

suficientes para suportar o crescimento bacteriano, conforme valores mínimos citados por SATTER e ROFFLER (1975) e KANG-MERZNARICH e BRODERICK (1981), de 3,3 a 8,5 mg/dL.

O modelo que melhor se ajustou à estimativa da concentração de protozoários do líquido ruminal $\hat{Y}_{\mathrm{pr}}$, em função dos níveis de concentrado (C), foi $\hat{\mathrm{Y}}_{\mathrm{pr}}=49,6286-0,5354 * \mathrm{C} \quad\left(\mathrm{R}^{2}=0,764\right.$; e $\left.\mathrm{P}<0,05\right) . \mathrm{Na}$ estimativa da concentração de protozoários ruminais, observou-se comportamento linear decrescente com os valores de $33,6 \times 10^{4}, 25,5 \times 10^{4}, 17,5 \times 10^{4}, 9,5 \times 10^{4}$ e $1,4 \times 10^{4}$ cél./mL, respectivamente, para os níveis de 30 , $45,60,75$ e $90 \%$ de concentrado. BIRD e LENG (1978), que trabalharam com novilhos Hereford faunados e defaunados, alimentados com feno de aveia suplementado ou não com concentrado à base de farelo de soja, verificaram depressão da biomassa de protozoários em $65 \%$, de $26 \times 10^{4}$ para $17 \times 10^{4}$ cél. $/ \mathrm{mL}$, próxima dos $68,6 \%$ de redução $(\mathrm{P}<0,05)$ obtidos entre os níveis de 45 e $60 \%$ de concentrado. O mesmo efeito foi relatado por BIRD et al. (1979), que trabalharam com ovinos alimentados com resíduos de aveia, suplementados com quatro níveis de concentrado à base de farinha de peixe, e observaram redução na contagem de protozoários ruminais de $80 \times 10^{4}$ para $49 \times 10^{4}$ cél./mL. Os resultados obtidos neste trabalho

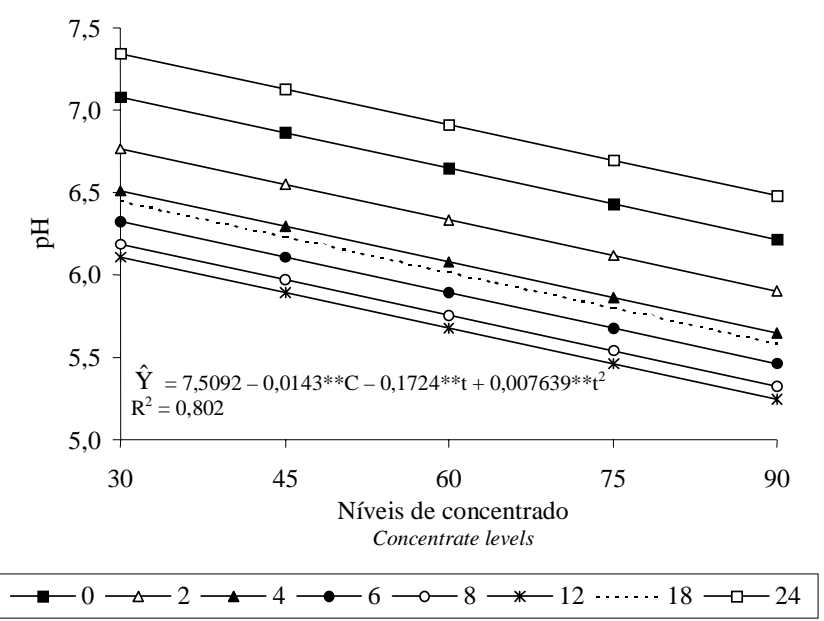

${ }^{* *}(\mathrm{P}<0,01)$ pelo teste $\mathrm{F}$ (by $F$ test); $\mathrm{C}=$ Nível de concentrado das dietas experimentais (Concentrate levels of experimental diets); $\mathrm{t}=$ Tempo pós-alimentação em horas (Post-feeding time in hours).

Figura 2 - Estimativas dos valores médios de $\mathrm{pH}$ do líquido ruminal, em função dos níveis de concentrado das dietas experimentais, para cada tempo pósalimentação, em horas.

Figure 2 - Estimates of rumen fluid $\mathrm{pH}$, as a function of the concentrate levels of the experimental diets, for each post-feeding time, in hours. estão em consonância com os de DIJKSTRA (1994), o qual afirmou que o fornecimento de ração com altos níveis de concentrado provocou redução drástica e até o desaparecimento do protozoários ruminais. $\mathrm{O}$ autor citou, entre as causas de degeneração e lise de protozoários, as dietas com altos níveis de carboidratos fermentescíveis, pela inabilidade desses microrganismos em controlar o excesso de engolfamento dos substratos solúveis e a conseqüente fermentação ácida intracelular. Diferenças foram observadas por LYLE et al. (1981), que forneceram a novilhos adaptados por 15 dias a dietas com $100 \%$ de concentrado e verificaram redução da população de protozoários ruminais de $14,3 \times 10^{4}$ cél. $/ \mathrm{mL}$, no primeiro dia, para $6,4 \times 10^{4}$ cél./mL no $21^{\text {o }}$ dia; após adaptação, este último valor foi intermediário às estimativas de $9,5 \times 10^{4}$ e $1,4 \times 10^{4}$ cél./mL obtidas para os níveis de 75 e $90 \%$ de concentrado, respectivamente.

A concentração de protozoários obtida quando os animais receberam 75 e $90 \%$ de concentrado está de acordo com TOWNE et al. (1990), os quais constataram que dietas com altos níveis de concentrado, sob condições de consumo ad libitum, reduziram ou eliminaram esses microrganismos do ambiente ruminal.

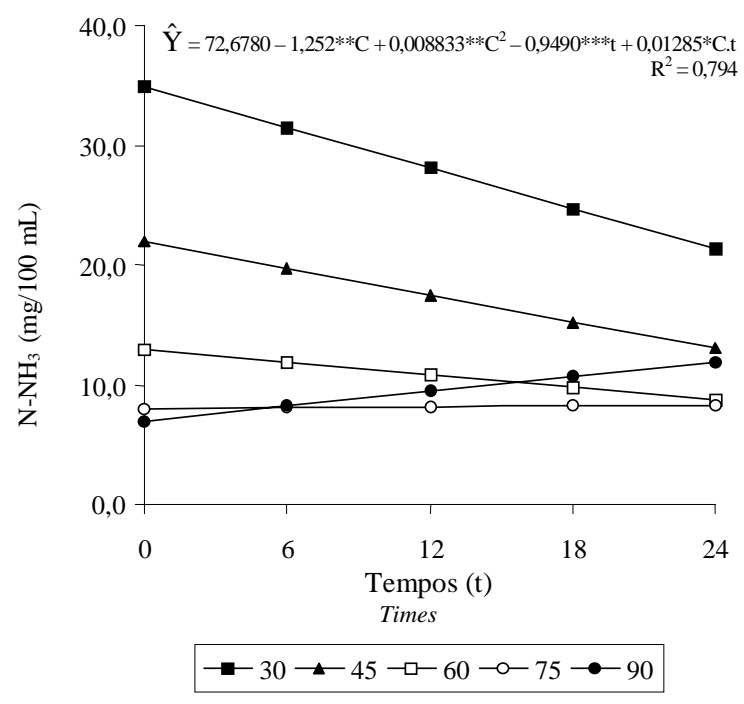

$(P<0,05) e^{* *}(P<0,01)$ pelo teste $F$ (by $F$ test); $C=$ Nível de concentrado das dietas experimentais (Concentrate levels of experimental diets); $\mathrm{t}$ = Tempo pós-alimentação em horas (Post-feeding time in hours).

Figura 3 - Estimativas das concentrações de amônia $\left(\mathrm{N}-\mathrm{NH}_{3}, \mathrm{mg} / \mathrm{dL}\right.$ ) no fluido ruminal, em função dos tempos pós-alimentação, em horas, para cada nível de concentrado (\%) das dietas experimentais.

Figura 3 - Estimates of the ammonia concentration $\left(\mathrm{N}-\mathrm{NH}_{3}\right.$, $\mathrm{mg} / \mathrm{dL}$ ) in ruminal fluid, as a function of the post-feeding time, in hours, for each concentrate levels in the experimental diets. 


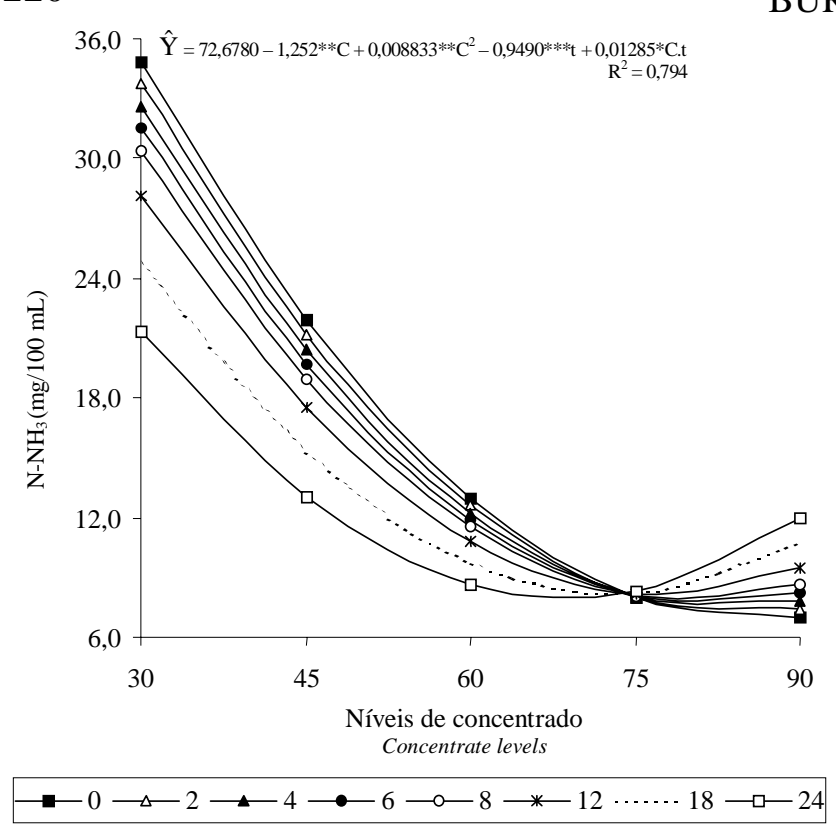

${ }^{* *}(P<0,05)$ e ** $(P<0,01)$ pelo teste $F$ (by $F$ test $) ; C=$ Nível de concentrado das dietas experimentais (Concentrate levels of experimental diets); $\mathrm{t}=$ Tempo pós-alimentação em horas (Post-feeding time in hours).

Figura 4 - Estimativas das concentrações de amônia ( $\mathrm{N}-\mathrm{NH}_{3}, \mathrm{mg} / \mathrm{dL}$ ) no fluido ruminal, em função dos níveis de concentrado das dietas experimentais, para cada tempo pós-alimentação, em horas.

Figure 4 - Estimates of the ammonia concentration $\left(\mathrm{N}-\mathrm{NH}_{3}, \mathrm{mg} /\right.$ $d L)$ in ruminal fluid, as a function of the concentrate levels in the experimental diets, for each post-feeding time, in hours.

A concentração de protozoários ruminais não foi influenciada pelos tempos pós-alimentação, à semelhança dos resultados obtidos por NANGIA e SHARMA (1994), que utilizaram bezerros búfalos com peso corporal entre 80 e $160 \mathrm{~kg}$, alimentados à base de feno de trigo picado e $40 \%$ de concentrado. Os autores não encontraram variação, nas amostragens de líquido ruminal pós-alimentação, nos tempos $2 ; 4 ; 6$;

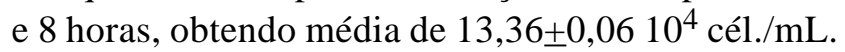

No tocante à composição das bactérias das amostras de líquido de rúmen, compostas por tratamento, o teor médio de MS bacteriana de $89,86 \%$ foi próximo do valor de $89,5 \%$, citado por RABELLO et al. (1996). Os teores de MO variaram de 90,38 a $93,26 \%$ e a média de $92,59 \%$ foi próxima às de 92,90 e 92,08\%, citadas por CARVALHO (1996) e DUTRA (1996). A concentração de N-total variou de 7,07 a $8,80 \%$, para os níveis de concentrado estudados, et al.

obtendo-se média de $8,25 \%$ similar ao valor médio de $8,03 \%$ relatado por VALADARES (1997) e intermediária aos valores de 7,6 e 10,4\%, citados pelo NRC (1985). Foi obtido valor médio de $9,67 \%$ para a concentração de EE bacteriano, interposto aos valores de 7,0 e $12 \%$, referidos pelo NRC (1985); este último valor foi citado também por RUSSELL et al. (1992). As concentrações de N-RNA variaram de 0,21 a $0,93 \%$, obtendo-se o valor médio de $0,57 \%$, abaixo da média de $1,22 \%$, encontrada por VALADARES (1997), mas inferior ao valor de 6,9\%, relatado por DUTRA (1996). Na análise de N-total dos padrões de levedura, obteve-se média de $14,52 \%$ na MS, utilizada para o cálculo do N-RNA.

Para os teores de RNA e N-RNA obtiveram-se médias de 3,93 e $0,57 \%$, próximas às relatadas por BERCHIELLI (1994), 3,24 e 0,47\%, e CLARK et al. (1992), que encontraram amplitudes, respectivamente, para RNA de 2,40 a $13,02 \%$ e para N-RNA de 0,35 a $1,89 \%$.

Os valores para a relação N-RNA/N-total foram baixos. Este fato, provavelmente, foi ocasionado pela presença residual de amido e extrato etéreo, após os procedimentos de centrifugações diferenciais das amostras de líquido ruminal para obtenção do isolado de células bacterianas; o amido, em consequiência da utilização de altos níveis de fubá de milho na formulação das dietas experimentais com níveis mais baixos de volumoso, conforme proporção percentual dos ingredientes, apresentados na Tabela 2, por BÜRGER et al. (2000), e o EE, possivelmente, pela contribuição do seu teor mais elevado nas rações, com altos níveis de concentrado, conforme Tabela 4 de BÜRGER et al. (2000). Para os cálculos da produção microbiana, assumiu-se o valor da relação N-RNA/N-total, de $8,84 \%$, resultante da média dos valores relativos aos níveis de 30, 45 e $60 \%$ de concentrado.

$\mathrm{O}$ consumo de compostos nitrogenados $\left(\mathrm{N}_{\text {ing }}\right)$, os fluxos de $\mathrm{N}$ total $\left(\mathrm{NT}_{\mathrm{abo}}\right), \mathrm{N}$ amoniacal $\left(\mathrm{NA}_{\mathrm{abo}}\right)$, nãoamoniacal $\left(\mathrm{NNA}_{\mathrm{abo}}\right), \mathrm{N}$ microbiano $\left(\mathrm{NM}_{\mathrm{abo}}\right)$ e $\mathrm{MS}$ bacteriana $\left(\mathrm{MSB}^{\mathrm{abo}}\right)$ no abomaso, as excreções de $\mathrm{N}$ fecal $\left(\mathrm{N}_{\text {fezes }}\right)$ e urinário $\left(\mathrm{N}_{\text {urina }}\right)$, as digestibilidades aparentes de $\mathrm{N}$ total (DAN), ruminal $\left(\mathrm{DPN}_{\text {rum }}\right) \mathrm{e}$ intestinal $\left(\mathrm{DP}_{\mathrm{Nint}}\right)$, a eficiência microbiana, em NM/ CHTDR (g/kg), MSB/CHTDR (g/kg) e NM/MODR $(\mathrm{g} / \mathrm{kg})$, o balanço de $\mathrm{N}$ e as respectivas equações de regressão e coeficientes de determinação podem ser observados na Tabela 1.

O consumo de $\mathrm{N}$ não foi influenciado pela elevação dos níveis de concentrado, observando-se o valor médio de $105,77 \mathrm{~g} /$ dia, o que era esperado, pois as 
Rev. bras. zootec.

Tabela 1 - Médias do consumo de compostos nitrogenados $\left(\mathrm{N}_{\text {ing }}\right)$, fluxos de $\mathrm{N}$ total, amoniacal, não-amoniacal e microbiano no abomaso ( $\mathrm{NT}_{\mathrm{abo}}, \mathrm{NA}_{\mathrm{abo}}, \mathrm{NNA}_{\mathrm{abo}}$, e $\mathrm{NM}_{\mathrm{abo}}$ ), matéria seca bacteriana no abomaso ( $\mathrm{MSB}_{\text {abo }}$ ), digestibilidades aparentes de $\mathrm{N}$ total, ruminal e intestinal (DAN, DPN rum e $\mathrm{DPN}_{\text {int }}$ ), carboidratos totais e matéria orgânica digeridos no rúmen (CHTDR e MODR) e eficiência microbiana em $\mathrm{NM}_{\mathrm{abo}} / \mathrm{CHTDR}, \mathrm{MSB}_{\mathrm{abo}} / \mathrm{CHTDR}$ e NM $\mathrm{Nbo} / \mathrm{MODR}$, em função dos níveis de concentrado das dietas experimentais

Table 1 - Means of the nitrogen compounds intake $\left(N_{\text {ing }}\right)$, total, ammonia, non-ammonia and microbial $N$, at abomasum $\left(N T_{a b o}, N A_{a b o}\right.$, $N N A_{a b o}$, e $\left.N M_{a b o}\right)$, bacterial dry matter $\left(M S B_{a b o}\right)$, apparent digestibilities of total, ruminal and intestinal $N\left(D A N, D P N_{\text {rum }} \in D P N_{\text {int }}\right)$, total carbohydrates and organic matter digestible at the rumen (CHTDR e MODR) and efficiency of microbial growth in NMabo/ CHTDR, MSB ${ }_{a b d}$ CHTDR e NM ${ }_{a b o}$ MODR according to concentrate levels of the experimental diets

\begin{tabular}{|c|c|c|c|c|c|c|}
\hline \multirow[t]{2}{*}{ Item } & \multicolumn{5}{|c|}{$\begin{array}{c}\text { Nível de concentrado }(\%) \\
\text { Concentrate level }\end{array}$} & \multirow[t]{2}{*}{$\begin{array}{l}\text { Regressão } \\
\text { Regression }\end{array}$} \\
\hline & 30 & 45 & 60 & 75 & 90 & \\
\hline $\mathrm{N}_{\text {ing }}(\mathrm{g} / \mathrm{dia})$ & 107,60 & 103,39 & 108,89 & 109,43 & 99,53 & $\hat{\mathrm{Y}}=105,77$ \\
\hline $\mathrm{NT}_{\mathrm{abo}}(\mathrm{g} / \mathrm{dia})$ & 88,72 & 95,55 & 108,40 & 127,14 & 114,58 & 1 \\
\hline $\mathrm{NA}_{\mathrm{abo}}^{\mathrm{a} o}$ (g/dia) & 5,12 & 3,80 & 5,34 & 5,08 & 4,08 & $\hat{Y}=4,68$ \\
\hline $\mathrm{NNA}_{a b o}(\mathrm{~g} / \mathrm{dia})$ & 83,61 & 91,61 & 103,07 & 120,58 & 110,97 & 2 \\
\hline $\mathrm{NM}_{\mathrm{abo}}(\mathrm{g} / \mathrm{dia})$ & 46,42 & 54,78 & 68,84 & 71,94 & 70,64 & 3 \\
\hline $\operatorname{MSB}_{a b o}(g / d i a)$ & 556,60 & 622,46 & 788,57 & 864,66 & 999,09 & 4 \\
\hline $\operatorname{DAN}(\%)$ & 71,63 & 65,75 & 64,75 & 69,44 & 72,14 & $\hat{Y}=68,74$ \\
\hline $\mathrm{DPN}_{\text {rum }}(\%) 10$ & 17,48 & 10,62 & 1,26 & $-12,91$ & $-12,91$ & 5 \\
\hline $\mathrm{DPN}_{\text {int }}(\%) 10$ & 65,31 & 59,98 & 62,94 & 72,67 & 75,06 & 6 \\
\hline CHTDR(kg/dia) & 1,49 & 1,38 & 1,57 & 1,60 & 1,63 & $\hat{\mathrm{Y}}=1,52$ \\
\hline MODR (kg/dia) & 1,35 & 1,38 & 1,46 & 1,43 & 1,48 & $\hat{\mathrm{Y}}=1,42$ \\
\hline $\mathrm{NM}_{\mathrm{abo}} / \mathrm{CHTDR}(\mathrm{g} / \mathrm{kg})$ & 32,01 & 39,46 & 44,16 & 44,40 & 46,97 & 7 \\
\hline $\mathrm{MSB}_{\mathrm{abo}} / \mathrm{CHTDR}(\mathrm{g} / \mathrm{kg})$ & 383,80 & 448,42 & 505,79 & 533,68 & 664,32 & 8 \\
\hline $\mathrm{NM}_{\mathrm{abo}} / \mathrm{MODR}(\mathrm{g} / \mathrm{kg})$ & 35,09 & 39,86 & 46,37 & 48,98 & 52,58 & 9 \\
\hline
\end{tabular}

1. $\hat{Y}=73,5627+0,5553^{*} \mathrm{C}, r^{2}=0,75 ; 2 . \hat{Y}=68,5635+0,5605^{\star} \mathrm{C}, \mathrm{r}^{2}=0,77 ; 3 . \hat{\mathrm{Y}}=36,2850+0,437294^{*} \mathrm{C}, \mathrm{r}^{2}=0,84 ; 4 . \hat{\mathrm{Y}}=315,399+7,5146^{* \star} \mathrm{C}$, $r^{2}=0,98 ; 5 . \hat{Y}=34,4379-0,5621^{* \star} C, r^{2}=0,95 ; 6 . \hat{Y}=54,3159+0,2146{ }^{*} \mathrm{C}, r^{2}=0,63 ; 7 . \hat{\mathrm{Y}}=27,4556+0,2324^{\star} \mathrm{C}, \mathrm{r}^{2}=0,87 ; 8 . \hat{\mathrm{Y}}=248,980$ $+4,3087^{* *} \mathrm{C}, \mathrm{r}^{2}=0,95 ; 9 . \hat{\mathrm{Y}}=26,9403+0,2939^{*} \mathrm{C}, \mathrm{r}^{2}=0,98 ; 10$. Percentagem do que chegou ao local (Percentage of the amount that arrived to the compartiment); ${ }^{*} \mathrm{e}^{* *}(\mathrm{P}<0,05)$ e $(\mathrm{P}<0,01)$ pelo teste $\mathrm{F}$ (by $\mathrm{F}$ test); e $\mathrm{C}=$ Nível de concentrado nas dietas experimentais (Concentrate level in the experimentaldiets).

dietas foram formuladas para o fornecimento de níveis semelhantes de PB (BÜRGER et al., 2000).

Os fluxos, no abomaso, de $\mathrm{NT}_{\mathrm{abo}}$, $\mathrm{NNA}_{\mathrm{abo}}$, e $\mathrm{NM}_{\text {abo }}$ aumentaram linearmente $(\mathrm{P}<0,05)$, enquanto o fluxo de $\mathrm{NA}_{\mathrm{abo}}$ não foi influenciado pelos níveis de concentrado, encontrando-se valor médio de 4,68 g/ dia (Tabela 1). Em consonância com os dados obtidos, JAAKKOLA e HUHTANEN (1993) observaram, respectivamente, efeito linear positivo $(\mathrm{P}<0,05)$ para $\mathrm{NT}_{\mathrm{abo}}, \mathrm{NNA}_{\mathrm{abo}}$ e $\mathrm{NM}_{\mathrm{abo}}$. O mesmo efeito foi relatado por WANDERLEY e THEURER (1983), os quais, ao fornecerem dietas contendo $80 \%$ de concentrado a novilhos, verificaram aumento do fluxo de $\mathrm{NT}_{\text {abo }}$. KRYSL et al. (1991) e JAAKKOLA e HUHTANEN (1993) relataram elevação do NA abo O mesmo foi mencionado por outros autores, que obtiveram respostas lineares crescentes para $\mathrm{NNA}_{\mathrm{abo}} \mathrm{e}$ $\mathrm{NM}_{\text {abo }}$ (RODE et al., 1985; PIWONKA, et al., 1994).

Ocorreu efeito linear crescente $(\mathrm{P}<0,01)$ para o teor de $\mathrm{MSB}_{\text {abo }}$ (Tabela 1). Estes resultados estão de acordo com CARVALHO (1996), o qual verificou que a quantidade de $\mathrm{MSB}_{\mathrm{abo}}$ aumentou linearmente com o nível de concentrado nas rações.
A excreção de $\mathrm{N}_{\text {fezes }}$ não foi influenciada pelos tratamentos experimentais, enquanto a $\mathrm{N}_{\text {urina }}$ apresentou comportamento linear decrescente $(\mathrm{P}<0,01)$ (Tabela 1).

Para as digestibilidades aparentes de N (Tabela 1), a DAN não foi influenciada pela elevação dos níveis de concentrado, sendo observado valor médio de $68,74 \%$, ao passo que a $D \mathrm{~N}_{\text {rum }}$ e a $\mathrm{DPN}_{\text {int }}$ apresentaram comportamento linear decrescente e crescente (respectivamente, $\mathrm{P}<0,01$ e $\mathrm{P}<0,05)$. A média de $68,74 \%$, encontrada para a DAN, foi próxima ao valor de 66,9\% referido por ROCHA (1997), que utilizou bezerros holandeses. Outros autores igualmente não observaram efeito sobre a DAN, em bezerros (PUNIA e SHARMA, 1988 [74,35\%]; JAAKKOLA e HUHTANEN, 1993 [74,03\%]).

Os resultados negativos obtidos para $\mathrm{DPN}_{\text {rum }}$ (Tabela 1) podem ser atribuídos à síntese microbiana, pela utilização de $\mathrm{N}$ endógeno por excesso de disponibilidade de energia, nos níveis mais elevados de concentrado das dietas. DUTRA (1996) relatou variação com redução da $\mathrm{DPN}_{\text {rum }}$, para rações com baixa e alta degradabilidades ruminais, similarmente 
ao observado na Tabela 1. CARVALHO (1996), que trabalhou com novilhos zebuínos, não encontrou variação para a $\mathrm{DPN}_{\mathrm{int}}$, obtendo valor médio de $58,10 \%$, intermediário aos coeficientes médios de 65,$31 ; 59,98$; e 62,94 , obtidos com os níveis de $30 ; 45$ e $60 \%$ de concentrado (Tabela 1).

As quantidades de carboidratos totais e matéria orgânica digeridos no rúmen (CHTDR e MODR) não sofreram influência dos níveis de concentrado, encontrando-se valores médios de 1,52 e 1,42 kg/dia (Tabela 1), similares aos encontrados por CARVALHO (1996), respectivamente, de 1,58 e 1,47 kg/dia. BERCHIELLI (1994) não obteve efeito dos tratamentos para MODR e CHTDR, ao contrário de outros autores, dentre eles RODE et al. (1985) e VAN VUUREN et al. (1993).

As eficiências de síntese de compostos nitrogenados microbianos, expressas em $\mathrm{g} \mathrm{NM}_{\mathrm{abo}} / \mathrm{kg}$ CHTDR, g MSB ${ }_{\text {abo }} / \mathrm{kg}$ CHTDR e g NM ${ }_{\text {abo }} / \mathrm{kg}$ MODR, (Tabela 2), apresentaram efeito linear positivo (respectivamente, $\mathrm{P}<0,05, \mathrm{P}<0,01$ e $\mathrm{P}<0,05$ ) com o aumento no nível de concentrados nas dietas. Estes resultados são coerentes com a elevação dos valores de $\mathrm{NM}_{\mathrm{abo}}$ e $\mathrm{MSB}_{\mathrm{abo}}$. PIWONKA et al. (1994), que trabalharam com novilhas holandesas alimentadas com rações contendo $25 \%$ de concentrado à base de farelo de soja e cevada moída e volumoso, obtiveram valor médio de 37,5 $\mathrm{g} \mathrm{NM}_{\mathrm{abo}} / \mathrm{kg} \mathrm{MODR}$, interposto às médias correspondentes aos níveis de 30 e $45 \%$ de concentrado, apresentadas na Tabela 1.

Os valores estimados obtidos para eficiência microbiana, para os níveis de 30 e $45 \%$ de concentrado (Tabela 1), foram compatíveis com as médias relatadas por LALLES e PONCET, (1990), 31,1 Nmic/ kg MODR; STOKES et al. (1991), 35,0 $\mathrm{g} \mathrm{NM}_{\mathrm{abo}} / \mathrm{kg}$ CHTDR; e VALADARES FILHO (1995), 30,4 g Nmic/kg MODR e 33,4 g NM ${ }_{\text {abo }} / \mathrm{kg}$ CHTDR.

Os valores de 483,9 $\mathrm{g} \mathrm{MSB}_{\mathrm{abo}} / \mathrm{kg}$ CHTDR referido por VALADARES FILHO (1995) e de $400 \mathrm{~g}$ MSBabo/kg CHTDR relatado por RUSSELL et al. (1992) encontram-se, respectivamente, interpostos aos valores obtidos com os níveis de 45 e $60 \%$ e 30 e $45 \%$ de concentrado.

\section{Conclusões}

Os valores de $\mathrm{pH}$ apresentaram comportamento quadrático, em função dos tempos de coleta, estimando-se os valores mínimos de 6,10;5,89; 5,67; 5,46 ; e 5,25 , às 11,3 horas após a alimentação, para os níveis de 30, 45, 60, 75 e $90 \%$ de concentrado. O aumento de concentrado nas dietas provocou reduções lineares nos valores de $\mathrm{pH}$.

A concentração de amônia ruminal foi reduzida linearmente para os tempos pós-alimentação, quando as rações continham 30,45 e $60 \%$ de concentrado, e aumentou linearmente para os níveis de 75 e $90 \%$, apresentando comportamento quadrático para os tempos pós-alimentação, estimando-se os valores mínimos de 6,$84 ; 7,14 ; 7,63 ; 7,82 ; 8,09 ;$ e $8,00 \mathrm{mg} / \mathrm{dL}$, com 86,$31 ; 84,86 ; 83,41 ; 81,95 ; 80,50 ; 77,59 ;$ e $68,86 \%$ de concentrado nas dietas.

A concentração de protozoários ruminais foi reduzida linearmente com o aumento dos níveis de concentrado na dieta, não sendo influenciada pelos tempos pós-alimentação.

As eficiências de síntese de compostos nitrogenados microbianos, em g NM ${ }_{\text {abo }} / \mathrm{kg}$ CHTDR, g MSB ${ }_{\text {abo }} / \mathrm{kg}$ CHTDR e $\mathrm{g} \mathrm{NM}_{\text {abo }} / \mathrm{kg}$ MODR, aumentaram linearmente com os níveis de concentrado nas dietas.

\section{Referências Bibliográficas}

ALDRICH, J.M., MUller, L.D., VARGA, G.A. 1993. Nonstructural carbohydrate and protein effects on rumen fermentation, nutrient flow, and performance of dairy cows. J. Dairy Sci., 76(4):1091-1105.

ALLEN, M.S. 1997.Relationship between fermentation acid production in the rumen and requirement for physically effective fiber. J. Dairy Sci., 80(7):1447-1462.

BATES, D.B., GILLETT, J.A., BARAO, S.A. 1985.The effect of specific growth rate and stage of growth on nucleic acidprotein values of pure cultures and mixed ruminal bacteria. $J$. Anim Sci., 61(3):713-724.

BERCHIELLI, T.T. Efeito da relação volumoso: concentrado sobre a partição da digestão, a síntese de proteína microbiana, produção de ácidos graxos voláteis e desempenho de novilhos em confinamento. Belo Horizonte: UFMG, 1994. 103p. Tese (Doutorado em Ciência Animal) - Universidade Federal de Minas Gerais, 1994.

BIRD S.H., HILL, M.K., LENG, R.A. 1979.The effects of defaunation on the rumen on the growth of lambs on lowprotein-high-energy diets. Br. J. Nutr., 42(1):81-87.

BIRD, S.H., LENG, R.A. 1978.The effects of defaunation of the rumen on the growth of cattle on low-protein high-energy diets. Br. J. Nutr., 40(1):163-167.

BÜRGER, P.J., PEREIRA, J.C., COELHO DA SILVA, J.F. et al. 2000. Consumo e digestibilidades aparentes total e parcial em bezerros holandeses alimentados com dietas contendo diferentes níveis de concentrado. Rev. bras. zootec., 29(1): 206-214.

CARVALHO, A.U. Níveis de concentrado na dieta de zebuínos: consumo, digestibilidade e eficiência microbiana. Viçosa, MG: UFV, 1996. 113p. Tese (Doutorado em Zootecnia) Universidade Federal de Viçosa, 1996.

CECAVA, M.J., MERCHEN, N.R., GAY, L.C. et al. 1990. Composition of ruminal bacteria harvested from steers as influenced by dietary energy level, feeding frequency, and isolation techniques. J. Dairy Sci., 73(9):2480-2488.

CLARK, J.H., KLUSMEYER, T.H., CAMERON, M.R. 1992. 
Rev. bras. zootec.

Microbial protein synthesis and flow of nitrogen fractions to the duodenum of dairy cows. J. Dairy Sci., 75(8):2304-2323.

COELHO DA SILVA, J.F., LEÃO, M.I. 1979. Fundamentos de nutrição dos ruminantes. Piracicaba: Livroceres. 380p.

DEHORITY, B. 1984. Evaluation of subsampling and fixation procedures used for counting rumen protozoa. Appl. Environ. Microbiol., 48(1):182-185.

DIJKSTRA, J. 1994. Simulation of the dynamics of protozoa in the rumen. Br. J. Nutr., 72(5):679-699.

DUTRA, A.R. Efeitos dos níveis de fibra e de fontes de proteínas sobre a digestão dos nutrientes e síntese de compostos nitrogenados microbianos em novilhos. Viçosa, MG: UFV, 1996. 118p. Dissertação (Mestrado em Zootecnia) Universidade Federal de Viçosa, 1996.

ERFLE, J.D., BOILA, R.J., TEATHER, R.M. et al. 1982. Effect of $\mathrm{pH}$ on fermentation characteristics and protein degradation by rumen microorganisms in vitro. J. Dairy Sci., 65(8):1457-1464.

FARIA, V.P., HUBER, J.T. 1984. Effect of dietary protein and energy levels on rumen fermentation in Holstein steers. $J$. Anim. Sci., 58(2):452-459.

FENG, P., HOOVER, W.H., MILLER, T.K. et al. 1993. Interactions of fiber and nonstructural carbohydrates on lactation and ruminal function. J. Dairy Sci., 76(5):1324-1333.

FENNER, H. 1965. Method for determining total volatile bases in rumen fluid by steam distillation. J. Dairy Sci., 48(2):249-251.

FERREIRA NETO, J.M., VIANA, E.S., MAGALHÃES, L.M. 1981. Patologia clínica veterinária. 2.ed. Belo Horizonte: Rabelo. 293p.

FRANZOLIN, R., DEHORITY, B.A. 1996. Efeitos do pH ruminal e ingestão alimentar na defaunação em ovinos sob rações concentradas. $R$. Soc. Bras. Zootec., 25(6):1207-1215.

GRIGSBY, K.N., KERLEY, M.S., PATERSON, J.A., et al. 1993. Combinations of starch and digestible fiber in supplements for steers consuming a low-quality bromegrass hay diet. J. Anim. Sci., 71(4):1057-1064.

HAGEMEISTER, H, LÜPPING, W. KAUFMANN, W. 1981.Microbial synthesis and digestion in the high-yielding dairy cow. In: HARESIGN, W. (Ed.) Recent advances in animal nutrition. London: Butterworths. p.31-48.

JAAKKOLA, S., HUHTANEN, P. 1993.The effects of forage preservation method and proportion of concentrate on nitrogen digestion and rumen fermentation in cattle. Grass Forage Sci., 48(2):146-154.

JOHN, A. 1984. Effects of feeding frequency and level of feed intake on chemical composition of rumen bacteria. J. Agric. Sci., 102(1):45-57.

KANG-MERZNARICH, J.H., BRODERICK, 1981. G.A. Effects of incremental urea supplementation on ruminal ammonia concentration and bacterial protein formation. $J$. Anim. Sci., 51(2):422-431.

KRYSL, L.J., JUDKINS, M.B., BOHMAN, V.R. 1991. Influence of ruminal or duodenal soybean oil infusion on intake, ruminal fermentation, site and extend of digestion, and microbial synthesis in beef heifers consuming grass hay. J. Anim. Sci., 69(6):2585-2590.

KUNG JR., L., TUNG, R.S., CARMEAN, B.R. 1992. Rumen fermentation and nutrient digestion in cattle fed diets varying in forage and energy source. Anim. Feed Sci. Technol., 39(1/2):1-2.

LALLES, J.P., PONCET, C. 1990. Changes in ruminal and intestinal digestion during and after weaning in dairy calves fed concentrate diets containing pea or soya bean meal. 1 . Digestion of organic matter and nitrogen. Lvstck. Prod. Sci.,
24(2):129-142.

LYLE, R.R., JOHSON, R.R., WILHITE, J.V. et al. 1981. Ruminal characteristics in steers as affected by adaptation from forage to all-concentrate diets. J. Anim. Sci., 53(5):1383-1390.

McALLAN, A.B. 1991. Carbohydrate and nitrogen metabolism in the forestomach of steers given untreated or ammonia treated barley straw diets supplemented with urea or urea plus fishmeal. Anim. Feed Sci. Technol., 33(3/4):195-208.

MEHREZ, A.Z., ØRSKOV, E.R., MCDONALD, I. 1977. Rates of rumen fermentation in relation to ammonia concentration. Br. J. Nutr., 38(3):437-443.

MERRY, R.J., McALLAN, A.B.A 1983. Comparison of the chemical composition of mixed bacteria harveted from the liquid and solid fractions of rumen digesta. Br. J. Nutr., 50(3):701-709.

MURPHY, T.A., FLUHARTY, F.L., LOERCH, S.C. 1994. The influence of intake level and corn processing on digestibility and ruminal metabolism in steers fed all-concentrate diets. $J$. Anim. Sci., 72(6):1608-1615.

NANGIA, O.P., SHARMA, R. 1994. Influence of niacin supplementation on rumen fermentation and microbial synthesis in buffaloes. Ind. Vet. J., 71(10):978-982.

NATIONAL RESEARCH COUNCIL - NRC. 1985. Ruminant nitrogen usage. 6.ed. rev., Washington, DC: National Academy of Sciences. $138 \mathrm{p}$.

ØRSKOV, E.R. 1994. Recent advances in understanding of microbial transformation in ruminants. Livest. Prod. Sci., 39(1):53-60.

ØRSKOV, E.R. 1986. Starch digestion and utilization in ruminants. J. Anim. Sci., 63(5):1624-1633.

ORTEGA, M.E., STERN, M.D., SATTER, L.D. 1979. The effect of rumen ammonia concentration on dry matter disappearance in situ. J. Dairy Sci., 62:76 (Suppl. 1).

OWENS, F.N., GOETSCH, A.L. Ruminal fermentation. 1988. In: CHURCH, D.C. The ruminant animal digestive physiology and nutrition. Englewood Cliffs: Prentice-Hall. p.145-171.

PIWONKA, E.J., FIRKINS, J.L., HULL, B.L. 1994. Digestion in the rumen and total tract of forage-based diets with starch or dextrose supplements fed to holstein heifers. J. Dairy Sci., 77(6):1570-1579.

POORE, M.H., MOORE, J.A., SWINGLE, R.S. 1990. Differencial passage rates and digestion of neutral detergent fiber from grain and forage in 30,60 and 90\% concentrate diets fed to steers. J. Anim. Sci., 68(10):2965-2973.

PUNIA, B.S., SHARMA, D.D. 1988.Effects of dietary energy source in complete feed on digestion and live-weight gain in buffalo and crossbred cattle calves. Ind. J. Anim. Sci., 58(6):715-720.

RABELLO, T.G., VALADARES FILHO, S.C., COELHO DA SILVA, J.F. et al. 1996. Grão de soja moído na alimentação de vacas em lactação III. Eficiência microbiana, amônia e pH. $R$. Bras. Soc. Zootec., 25(2):270-281.

RINNE, M., JAAKKOLA, S., HUHTANEN, P. 1997. Grass maturity on cattle fed silage-based diets. 1. Organic matter digestion, rumen fermentation and nitrogen utilization. Anim. Feed. Sci. Technol., 67(1):1-17.

ROBINSON, P.H., GILL, M., KENELLY, J.J. 1997.Influence of time of feeding a protein meal on ruminal fermentation and forestomach digestion in dairy cows. J. Dairy Sci., 80(8):1366-1373.

ROBINSON, P.H., TAMMINGA, S., VAN VUUREN, A.M. 1986. Influence of declining level of feed intake and varying the proportion of starch in the concentrate on rumen fermentation 
in dairy cows. Lvstck. Prod. Sci., 15(2):173-179.

ROCHA, E.O. Estudo de desaleitamento precoce, exigências nutricionais e características produtivas de bovinos de origem leiteira para corte. Viçosa, MG: UFV, 1997. 152p. Tese (Doutorado em Zootecnia) - Universidade Federal de Viçosa, 1997.

RODE, L.M., WEAKLEY, D.C., SATTER, L.D. 1985.Effect of forage amount and particle size in diets of lactating dairy cows on site of digestion and microbial synthesis. Can. J. Anim. Sci., 65(1):101-111.

RUSSELL, J.B., O'CONNOR, J.D., FOX, D.G. et al. 1992. A net carbohydrate and protein system for evaluating cattle diets: I. Ruminal fermentation. J. Anim. Sci., 70(11):3551-3561.

SATTER, L.D., ROFFLER, R.E. 1975. Nitrogen requirement and utilization in dairy cattle. J. Dairy Sci., 58(8):1219-1237.

SILVA, D.J. 1990. Análise de alimentos (Métodos químicos e biológicos). 2.ed. Viçosa, MG: UFV. 165p.

STERN, M.D., HOOVER, W.H. 1979. Methods for determining and factors affecting rumen microbial synthesis: a review. $J$. Anim. Sci., 49(6):1590-1603.

STOKES, S.R., HOOVER, W.H., MILLER, T.K. et al. 1991. Ruminal digestion and microbial utilization of diets varying in type of carbohydrate and protein. J. Dairy Sci., 74(3):871-881.

TOWNE, G., NAGARAJA, T.G., BRANDT JR., R.T., et al. 1990. Ruminal ciliated protozoa in cattle fed finishing diets with or without fat. J. Anim. Sci., 68(7):2150-2155.

UNIVERSIDADE FEDERAL DE VIÇOSA. 1997. SAEG - Sistema de análises estatísticas e genéticas. Versão 7.1. Viçosa, MG, 150p. (Manual do usuário).

USHIDA, K., LASSALAS, B., JOUANY, J.P. 1985. Determination of assay parameters for RNA analysis in bacterial and duodenal samples by spectrophotometry. Influence of sample treatment and preservation. Reprod. Nutr. Dévelop., 25(6):1037-1046.

VALADARES FILHO, S.C. 1995. Eficiência de síntese de proteína microbiana, degradação ruminal e digestibilidade intestinal de proteína bruta, em bovinos. In: SIMPÓSIOINTERNACIONAL SOBRE EXIGÊNCIAS NUTRICIONAIS EM RUMINANTES, 1995, Viçosa, MG. Anais... Viçosa: JARD, p.355-388.
VALADARES, R.F.D. Níveis de proteína em dietas de bovinos: consumo, digestibilidade, eficiência de síntese microbiana, amônia ruminal, uréia plasmática e excreções de uréia e creatinina. Belo Horizonte: UFMG, 1997. 101p. Tese (Doutorado em Ciência Animal) - Universidade Federal de Minas Gerais, 1997.

VAN VUUREN, A.M., VAN DER KOLEN, C.J., VROONS-DE BRUIN, J. 1993. Ryegrass versus corn starch or beet pulp fiber diet effects on digestion and intestinal amino acids in dairy cows. J. Dairy Sci., 76(9):2692-2700.

VIEIRA, P.F. Efeito do formaldeído na proteção de proteínas e lipídios em rações para ruminantes. Viçosa, MG: UFV, 1980, 98p. Tese (Doutorado em Zootecnia) - Universidade Federal de Viçosa, 1980.

WANDERLEY, R.C., THEURER, C.B. 1983. Fluxo de proteína do rúmen para o duodeno de novilhos alimentados com dieta volumosa e dieta concentrada. Pesq. Agropec. Bras., 18(5):543-549.

WARNER, A.C.I. 1962. Enumeration of rumen micro-organisms. J. Gen. Microbiol., 28(1):119-128.

ZINN, R.A., OWENS, F.N. 1986. A rapid procedure for purine measurement and its use for estimating net ruminal protein synthesis. Can. J. Anim. Sci., 66(1):157-166.

Recebido em: 01/03/99

Aceito em: 02/08/99 